\title{
Campo Conceitual Aditivo: um estudo com professoras dos anos iniciais do Ensino Fundamental
}

\author{
Additive Conceptual Field: a study on elementary school teachers
}

\author{
Teresa Cristina Etcheverria ${ }^{1}$ \\ Tânia Maria Mendonça Campos ${ }^{2}$ \\ Angélica Fontoura Garcia Silva ${ }^{3}$
}

\begin{abstract}
Resumo
Este artigo discute os resultados da pesquisa de doutorado intitulada: $O$ ensino das Estruturas Aditivas junto a professoras dos anos iniciais do Ensino Fundamental. Seu objetivo foi identificar e compreender, no contexto de um grupo de discussão, as contribuições de um estudo do Campo Conceitual Aditivo nas aprendizagens matemáticas de professoras dos anos iniciais do ensino fundamental. A pesquisa teve abordagem qualitativa, a qual se apoiou em dados quantitativos. As análises usam dados coletados nos problemas aplicados aos estudantes, nos problemas elaborados pelas professoras e naqueles presentes no livro de Matemática usado na escola e, também, nas discussões realizadas nos encontros. Os resultados revelam que, durante o estudo, as professoras ampliaram suas perspectivas sobre a natureza de problemas no campo aditivo, produzindo um equilíbrio na quantidade de problemas elaborados nas categorias: composição, transformação e comparação.
\end{abstract}

Palavras-chave: Professoras. Anos Iniciais do Ensino Fundamental. Estruturas Aditivas. Grupo de Discussão.

\begin{abstract}
This article discusses the results of a doctoral thesis entitled: "The teaching of additive structures among elementary school teachers." It aims to identify and understand the contributions associated with the undertaking of a study of the Additive Conceptual Field in mathematics learning of elementary school teachers who participated in a discussion group. The research adopted a broadly qualitative approach, in which quantitative data was also considered. The analyses were based on the resolutions of problems administered to students, problems produced by teachers and those drawn from mathematics textbooks used in the school, as well as data collected during group discussions. The results indicate that, during the study, the teachers amplified their perspectives on the nature of problems associated with the additive field, producing a balanced quantity of problems in the categories: composition, transformation, and comparison.
\end{abstract}

Keywords: Teachers. Elementary School. Additive Structures. Discussion Group.

${ }^{1}$ Doutora em Educação Matemática pela Universidade Anhanguera de São Paulo (UNIAN). Professora do
Departamento de Matemática da Universidade Federal de Sergipe (UFS), Itabaiana, Sergipe, Brasil. Endereço
para correspondência: Rua Maria Oliveira Mendonça, 1811, Bairro Anísio Amâncio de Oliveira, CEP 49500-
000, Itabaiana, Sergipe, Brasil. E-mail: tetcheverria @mail.com
${ }^{2}$ Pós-doc em Matemática pela Universidade de Londres e em Educação Matemática pela Universidade de
Oxford, Inglaterra. Coordenadora do Programa de Pós-Graduação em Educação Matemática da Universidade
Anhanguera de São Paulo (UNIAN), São Paulo, São Paulo, Brasil. Endereço para correspondência: Rua Dr.
Fausto Ferraz, $\quad 61, \quad$ apto. 151, CEP 01333-030, São Paulo, São Paulo, Brasil. E-mail:
taniammcampos@ hotmail.com
${ }^{3}$ Doutora em Educação Matemática pela Pontifícia Universidade Católica de São Paulo (PUC). Professora do
Programa de Pós-Graduação em Educaçãa Matemática da Universidade Anhanguera de São Paulo (UNIAN),
São Paulo, São Paulo, Brasil. Endereço para correspondência: Rua Antônio Celeguim, 180, CEP 07850-060,
Franco da Rocha, São Paulo, Brasil. E-mail: angelicafontoura@gmail.com Bolema, Rio Claro (SP), v. 29, n. 53, p. 1181-1200, dez. 2015 


\section{Introdução}

Neste artigo apresentamos alguns resultados da tese de doutorado da primeira autora (ETCHEVERRIA, 2014), que teve como objetivo identificar e compreender contribuições de um estudo do Campo Conceitual Aditivo, baseado na Teoria dos Campos Conceituais e na reflexão sobre a ação docente frente à resolução de problemas aditivos, junto a professoras dos anos iniciais do Ensino Fundamental, por meio de grupos de discussão.

A motivação para uma investigação deste tipo veio da nossa relação com as professoras dos anos iniciais do Ensino Fundamental na execução de outros projetos, e da constatação, feita por Reges (2006), de que as docentes desse nível de ensino desconhecem a Teoria dos Campos Conceituais (TCC); não dão importância à variedade de situações apresentadas por Vergnaud (1996a); atribuem importância à tabuada e ao trabalho com o algoritmo da adição e da subtração, como única forma de representação; e apresentam dificuldades quando as situações apresentadas nos problemas exigem raciocínios mais sofisticados.

Assim, com vistas a contribuir nesse contexto, relacionado ao ensino da resolução de problemas aditivos em turmas dos anos iniciais do Ensino Fundamental, trazemos para discussão alguns resultados de um estudo do Campo Conceitual Aditivo realizado com professoras dos anos iniciais do Ensino Fundamental.

Nesse estudo com as professoras, antes de constituir o grupo de discussão com as mesmas, realizamos um diagnóstico para conhecer a realidade do contexto educacional envolvido frente ao ensino e aprendizado da resolução de problemas aditivos. Para tanto, aplicamos um instrumento com dez problemas aditivos a 248 estudantes do $2^{\circ}$ ao $5^{\circ}$ ano das 11 turmas dos anos iniciais do Ensino Fundamental da escola escolhida, e solicitamos às professoras desses estudantes que elaborassem seis problemas de adição ou subtração. A aplicação do instrumento aconteceu no mesmo dia para alunos e professoras e, nesse mesmo dia, coletamos um exemplar de cada ano escolar $\left(2^{\circ}\right.$ ao $5^{\circ}$ ano $)$ do livro de Matemática adotado pela escola.

De posse dos dados coletados no primeiro momento, constituímos o grupo de discussão com as professoras dos anos iniciais do Ensino Fundamental da escola envolvida. No período de Fev./2012 a Nov./2012, foram realizados oito encontros de estudos do Campo Conceitual Aditivo com base na Teoria dos Campos Conceituais (TCC). Os dados relativos ao desempenho dos estudantes nos dez problemas, as estratégias utilizadas por eles nas 
resoluções dos problemas, a classificação dos problemas elaborados pelas professoras e os do livro de Matemática adotado pela escola serviram para provocar discussões e reflexões dos processos de ensino e de aprendizagem das Estruturas Aditivas. O estudo no grupo de discussão começou com a participação de oito professoras, mas somente quatro permaneceram até o final do trabalho.

No mês seguinte à conclusão do estudo com as professoras, houve uma segunda aplicação do instrumento com dez problemas aos estudantes, e, após seis meses, foi realizada uma terceira aplicação desse instrumento. Nas mesmas datas das reaplicações do instrumento aos estudantes, também as professoras novamente elaboraram seis problemas aditivos. Os dados coletados nessas reaplicações foram comparados com os dados da primeira aplicação. Para tanto, metodologicamente, nosso estudo fez uso de uma abordagem qualitativa a qual se apoiou em dados quantitativos.

\section{Aprendizagens de professoras dos anos iniciais do Ensino Fundamental em um grupo de discussão}

A pouca ou inexistente discussão de pesquisas que refletem sobre as mudanças curriculares no ensino da Matemática (teorias e práticas pedagógicas que as embasam) no processo de formação docente fazem com que as novas propostas de ensino não cheguem à sala de aula, o que ocasiona que muitas professoras somente reproduzam o modelo de ensino que vivenciaram enquanto estudantes. Esse fato contribui para que se consolide uma cultura de aula pautada numa rotina de ensino quase homogênea e num currículo que não contempla os fundamentos de ensino propostos nas discussões contemporâneas da área da Educação Matemática, o que leva muitas professoras dos anos iniciais do Ensino Fundamental a continuarem com a abordagem de décadas anteriores, cuja prioridade estava na resolução de cálculos e algoritmos desprovidos de compreensão e de significado para os alunos. (NACARATO; MENGALI; PASSOS, 2009).

Segundo Abrantes, Serrazina e Oliveira (1999, p.27), “o professor é o elemento chave na criação do ambiente que se vive na sala de aula. Cabe-lhe a responsabilidade de propor e organizar as tarefas a realizar e de coordenar o desenvolvimento das actividades dos alunos", o que requer um conhecimento do conteúdo a ensinar.

Em seus estudos, Vergnaud (1996b) destaca que quando nos voltamos para o que ocorre dentro da sala de aula se faz necessário interessar-se pelo conteúdo a ser ensinado, ou 
seja, pelo conteúdo do conhecimento. O autor afirma que desenvolveu "a teoria dos campos conceituais para tentar melhor compreender os problemas de desenvolvimento específicos no interior de um mesmo campo de conhecimento" (VERGNAUD, 1996b, p.11). A discussão do conteúdo do conhecimento e da forma como se dá o seu ensino oportuniza uma aprendizagem às professoras, "contudo, a experiência e o envolvimento de cada um é que irá determinar o quanto esse estudo será ou não útil para o mesmo" (VERGNAUD, 1996c, p.68). Não podemos afirmar o quanto as discussões no grupo podem ser aproveitadas na ação docente, pois, para tanto, se faz necessária a transformação do saber de referência de cada professora em um conhecimento a ser ensinado. O conhecimento a ser ensinado é aquele indicado sob a forma de programa, no caso das professoras deste estudo, pela Secretaria de Educação do Município. É preciso, então, que ocorra a transformação do conhecimento a ser ensinado, aquele previsto no programa de Matemática daquele ano escolar, em ensinamento efetivamente ensinado na sala de aula (VERGNAUD, 1996c).

Assim, para que se efetive uma aprendizagem, as professoras precisam vivenciar situações que desafiem suas ideias prévias, possibilitando que reflitam sobre a ação docente praticada diariamente na sala de aula. A discussão no coletivo do grupo oportuniza que se construam saberes advindos da reflexão sobre a experiência dos colegas e, principalmente, sobre sua própria experiência, o que, na opinião de Zeichner (2008), possibilita a compreensão e a melhoria do processo de ensino, entendido por nós como mudança e desenvolvimento profissional. Para Polettini (1998), do ponto de vista construtivista, a mudança e o desenvolvimento do professor podem ser pensados como aprendizagem do professor.

Serrazina (1998, p. 136) contribui nessa discussão com o que ela chama de "refletir e ganhar confiança". Para a autora, a reflexão individual ou em grupo estimula a compreensão sobre o processo de ensino da Matemática e o grupo possibilita que o professor sinta-se mais seguro para mudar suas práticas pedagógicas. A autora ainda destaca que o desenvolvimento profissional ocorre em um movimento espiral, que se articula por meio da ação-reflexão-ação entre os aspectos relacionados à construção de conhecimentos profissionais do professor, em relação ao conteúdo, à forma como ele ensina, suas concepções e à forma como ele mesmo se apropria do novo conhecimento, o que pode provocar mudanças.

\section{Campo Conceitual Aditivo - objeto de estudo no grupo de discussão}


Vergnaud (1982) define campo conceitual como um conjunto de situações cujo domínio requer a apropriação de outros conceitos de naturezas distintas. No caso deste estudo, devemos ter em mente que a compreensão dos conceitos que envolvem as operações de adição e de subtração não surge a partir de uma única situação. Para que tal compreensão ocorra, torna-se necessário que o indivíduo depare-se com diversas e distintas situações, pois "os conceitos matemáticos traçam seus sentidos a partir de uma variedade de situações, e cada situação normalmente não pode ser analisada com a ajuda de apenas um conceito" (MAGINA et al., 2008, p. 8).

A definição de um conceito está vinculada ao conjunto de situações que constituem as referências de suas diferentes propriedades e ao conjunto de esquemas utilizados pelos sujeitos nessas situações (VERGNAUD, 1996a).

A ação operatória envolve a utilização de significantes explícitos (palavras, enunciados, símbolos e signos) e isso é indispensável à conceitualização o que, segundo Vergnaud (1996a) conduz a considerar que a formação de um conceito está apoiada em um tripé de conjuntos ( $\mathrm{S}, \mathrm{I}, \mathrm{R})$, no qual $\mathrm{S}$ é um conjunto de situações, que dão sentido ao conceito (a referência); I é um conjunto de invariantes sobre os quais repousa a operacionalidade dos esquemas (o significado); e $\mathrm{R}$ é um conjunto de formas, que permitem representar simbolicamente o conceito, as suas propriedades, as situações e os procedimentos de tratamento (o significante).

Neste estudo, as situações (S) envolvidas dão sentido aos conceitos do Campo Conceitual Aditivo; os invariantes operatórios (I) dão significado aos procedimentos operatórios envolvidos na resolução dos problemas aditivos, representados pelos estudantes, na maioria das vezes, pelo cardinal da soma ou da subtração, os significantes (R).

Para esclarecer, ilustramos o tripé no qual estão amparados os conceitos parte e todo. Para tanto, apresentamos duas resoluções de estudantes do $3^{\circ}$ ano do Ensino Fundamental para a seguinte situação-problema: Um aquário tem 13 peixes de cor dourada e cinza. Cinco peixes são dourados. Quantos são os peixes cinza?

\begin{tabular}{|c|c|c|c|}
\hline \multicolumn{2}{|c|}{ Estudante 1} & \multicolumn{2}{|c|}{ Estudante 2} \\
\hline Resolução & Resposta & Resolução & Resposta \\
\hline 13 & & 5 & \\
\hline$\frac{-5}{8}$ & Tem 8 peixes cinza & $\frac{+8}{13}$ & 8 peixes \\
\hline
\end{tabular}

A situação (S) apresentada tem como propósito dar sentido aos conceitos parte-todo. Os dois estudantes evidenciam conhecer esses conceitos, contudo, as representações (R) 
explícitas nos cálculos numéricos, representados por eles, revelam indícios de que os esquemas utilizados não foram os mesmos. A estratégia utilizada pelo Estudante 1, sinaliza que ele compreende que se tirarmos uma parte de um todo, sobra a outra parte (I). Já o cálculo numérico representado pelo estudante 2 , indica que ele compreendeu que a soma das partes é igual ao todo (I). É possível perceber que os invariantes operatórios têm relação com as representações utilizadas pelos estudantes e com os conceitos presentes na situação.

Vergnaud (1996a) afirma que a classificação das relações de base e das classes de problemas permite que se estude além do presente nas situações habituais da vida, ou seja, possibilita que as professoras identifiquem as classes de problemas que os estudantes já dominam e proponham novas situações-problema, oportunizando a expansão do conhecimento do campo conceitual aditivo.

No estudo das estruturas Aditivas, Vergnaud (1996a) identificou seis relações de base a partir das quais é possível elaborar problemas de adição e de subtração da aritmética comum.

I. A composição de duas medidas numa terceira.

II. A transformação (quantificada) de uma medida inicial numa medida final.

III. A relação (quantificada) de comparação entre duas medidas.

IV. A composição de duas transformações.

V. A transformação de uma relação.

VI. A composição de duas relações. (VERGNAUD, 1996a, p.172)

O estudo desses diferentes tipos de situações aditivas, habitualmente, não é feito nos anos iniciais do Ensino Fundamental; entretanto ele é muito importante porque cada um deles apresenta dificuldades distintas (VERGNAUD, 2009).

As situações aditivas são relações ternárias, isto é, são relações que ligam três elementos entre si. Por exemplo: três mais quatro é igual a sete. Relações ternárias podem ser encadeadas de diversas maneiras, como vimos nas seis relações apresentadas por Vergnaud (1996a), e resultar em diferentes estruturas aditivas. Neste trabalho temos nosso foco apenas nas três primeiras classes de esquemas ternários fundamentais: composição (I), transformação (II) e comparação (III).

Magina et al. (2008) contribuem nessa discussão ao reconhecerem as diferentes dificuldades presentes nas três primeiras categorias e apresentarem uma classificação das mesmas em subcategorias (protótipo e extensões), com vistas a possibilitarem aos professores um melhor entendimento sobre a formação e o desenvolvimento de conceitos do Campo Aditivo por parte dos alunos. 
Assim, para destacar os diferentes raciocínios presentes nas situações, Magina et al. (2008) fazem uma discussão sobre os tipos de problemas, considerando o grau de complexidade dos mesmos.

Os problemas de menor complexidade são chamados de problemas protótipos. Neles, encontramos situações que envolvem conceitos de duas categorias diferentes: composição e transformação. Nos protótipos de composição, temos duas partes e queremos saber o todo, por exemplo: A mãe de Paulo foi à feira e comprou 7 maçãs e 5 peras. Quantas frutas a mãe de Paulo comprou na feira?

Nos problemas protótipos de transformação, conhecemos o estado inicial, a transformação e queremos encontrar o estado final, por exemplo: Antônio tinha 8 carrinhos. Seu pai lhe deu 2 carrinhos. Com quantos carrinhos Antônio ficou? As situações prototípicas de transformação podem estar relacionadas a um esquema de juntar, quando há ganho, ou ao esquema de retirar, quando há perda. Os esquemas utilizados por uma criança na resolução das situações prototípicas se desenvolvem em situações do cotidiano, por exemplo: ao contar quantas pessoas têm numa casa, quantos talheres e pratos são necessários para o almoço, quantos brinquedos cada criança tem etc.

Os problemas de $1^{\mathrm{a}}$ extensão também envolvem esses dois tipos de situações e apresentam maior complexidade que os problemas protótipos. Eles podem ser de composição com uma das partes desconhecida, por exemplo: Moema tem 13 doces, sendo balas $e$ chicletes. Sete são balas, quantos são os chicletes? Nesse caso, o todo e uma das partes são conhecidos e, a partir da subtração destes, descobre-se a parte desconhecida.

Os problemas de $1^{\mathrm{a}}$ extensão também podem ser de transformação com a transformação desconhecida, isto é, conhece-se o estado inicial e final e procura-se a transformação ocorrida, por exemplo: Na prateleira da escola, havia 15 livros. Foram colocados alguns livros nessa prateleira e agora há 22 livros nela. Quantos livros foram colocados na prateleira?

As situações-problemas de $2^{a}$ e $3^{a}$ extensão envolvem conceitos de comparação. Nas situações de comparação há uma comparação entre duas medidas; nelas, a relação ternária se compõe de um referente (valor de referência), de um referido (valor do outro grupo) e da relação entre os dois grupos.

Numa situação de $2^{a}$ extensão, são conhecidos o referente e a relação e temos que obter o valor do referido, por exemplo: Vitória tem 18 figurinhas e Roberta tem 6 figurinhas a menos que Vitória. Quantas figurinhas tem Roberta? Nessas situações, o referido tanto pode 
ter uma medida a mais ou a menos do que o referente, por isso a solução pode ser uma adição ou uma subtração. Independente disso, para que o estudante compreenda a situação e a resolva corretamente, precisa perceber a relação como uma comparação das medidas.

Numa situação de $3^{a}$ extensão, conhecemos os dois grupos (referente e referido) e desconhecemos a relação entre eles, por exemplo: Graziela e Juliana ganharam bombons de presente. Graziela ganhou 5 bombons e Juliana ganhou 11 bombons. Quem ganhou mais bombons? Quantos bombons a mais? A primeira pergunta é mais fácil para as crianças porque basta que elas identifiquem corretamente os valores numéricos. Contudo, para responder à segunda pergunta a criança precisa entender que a resposta "se refere à diferença entre as quantidades e não as quantidades propriamente ditas" (MAGINA et al., 2008, p.44).

$\mathrm{Na} 4^{\mathrm{a}}$ extensão, novamente temos problemas que envolvem duas categorias: transformação e comparação. Eles apresentam um nível de complexidade maior do que os problemas das extensões anteriores. Nos problemas de transformação - $4^{\mathrm{a}}$ extensão, são conhecidos o estado final e a transformação, e desconhece-se o estado inicial, por exemplo: Michel tinha alguns bonés. Ganhou de aniversário 4 bonés, ficando com 11 bonés. Quantos bonés Michel tinha antes?

Nos problemas de comparação - $4^{\mathrm{a}}$ extensão, são conhecidos o referido e a relação e se desconhece o referente, por exemplo: Carla e Rita têm reais guardados em seus cofrinhos. Rita guardou 6 reais a menos que Carla. Sabendo que Rita guardou 14 reais, quantos reais Carla guardou? Esse tipo de problema apresenta um grau maior de complexidade, pois o referente é desconhecido, isto é, não sabemos quanto dinheiro Carla tem.

Essa variedade de situações com diferentes graus de complexidade exige que o professor tenha clareza das dificuldades presentes nos problemas que propõe, para não ficar repetindo situações que exigem do aluno sempre o mesmo raciocínio. Cabe a ele propor uma ação planejada que oportunize a vivência de um conjunto de situações que envolvam conceitos de naturezas distintas para evitar o insucesso de seus alunos na resolução dos mesmos.

A possibilidade de as professoras estudarem aspectos destacados, tais como: categorias, classes de situações em cada categoria, forma de apresentação das situações e das relações nelas contempladas, pode provocar mudanças nos processos de ensino e de aprendizagem do Campo Aditivo. 


\section{Análise dos dados coletados antes do estudo com as professoras}

Como já informado anteriormente, antes da experiência de ensino com as professoras foi realizado um estudo diagnóstico para conhecimento do contexto investigado com relação ao ensino e ao aprendizado da resolução de problemas aditivos.

Quanto ao desempenho dos estudantes, o Gráfico 1 mostra que o mesmo foi crescente do $2^{\circ}$ ao $5^{\circ}$ ano, o que era esperado, tendo em vista o grau de maturidade e o conhecimento adquirido a cada ano. $\mathrm{O}$ índice geral de acertos dos alunos do $2^{\circ}$ e $3^{\circ}$ anos foi abaixo de $50 \%$. A diferença entre os percentuais de acertos foi menor do $4^{\circ}$ para o $5^{\circ}$ ano $(5 \%)$ e maior do $3^{\circ}$ para o $4^{\circ}$ ano $(20 \%)$. A diferença do $2^{\circ}$ para o $5^{\circ}$ ano foi de $32 \%$. A turma do Acelera, composta por estudantes que têm dois ou mais anos de defasagem em relação à idade regular para a série na qual se encontram, teve um índice de desempenho de 50\%.

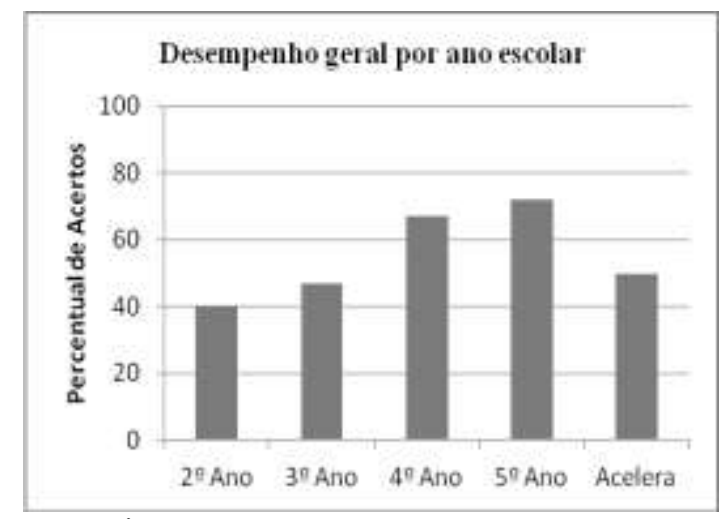

Gráfico 1 - Desempenho dos estudantes por ano escolar

Fonte: Etcheverria, 2014, p. 89

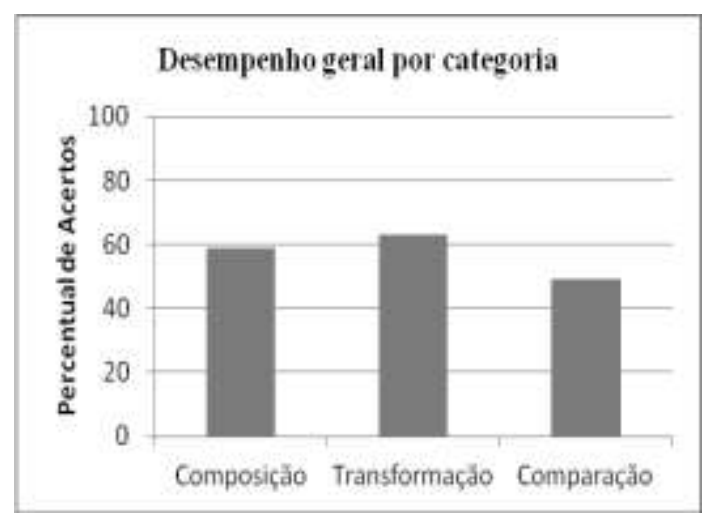

Gráfico 2 - Desempenho dos estudantes por categoria

Fonte: Etcheverria, 2014, p.90

Observando-se o desempenho por categoria, no Gráfico 2, percebe-se que o maior número de acertos ocorreu na categoria transformação (63\%) e o menor na categoria comparação (49\%). O desempenho na categoria composição (59\%) ficou um pouco abaixo da categoria transformação, com uma diferença de $4 \%$.

Os resultados da análise dos problemas elaborados pelas professoras e dos problemas presentes no livro de Matemática adotado pela escola estão representados nos Gráficos 3 e 4 . O Gráfico 3 deixa evidente que o maior número de problemas elaborados pelas professoras foi na categoria transformação $(52,3 \%)$, seguida pela categoria composição $(34,1 \%)$ e, por último, a categoria comparação $(13,6 \%)$. 


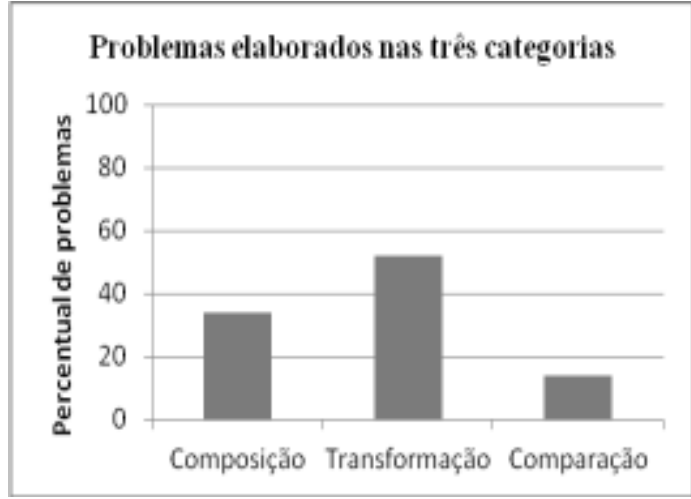

Gráfico 3 - Categorização dos problemas elaborados pelas professoras

Fonte: Etcheverria, 2014, p.122

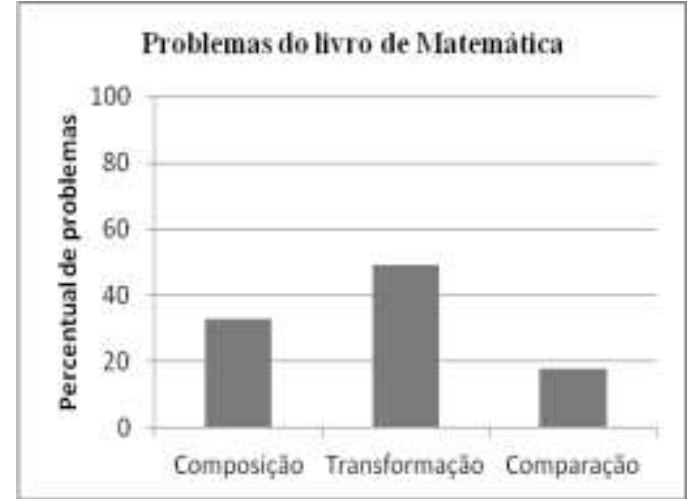

Gráfico 4 - Categorização dos problemas do livro de Matemática

Fonte: Etcheverria, 2014, p.130

Vale destacar que, do total de problemas classificados nas categorias de composição e transformação, 84\% são do tipo protótipo. Para Vergnaud (1996a), os esquemas utilizados pela criança na resolução das situações prototípicas se desenvolvem em seu cotidiano ainda antes dela começar sua trajetória escolar e, a partir desses esquemas de ação, elas começam a compreender as operações de adição e de subtração. Por esse motivo, é esperado que estudantes de todos os anos do Ensino Fundamental se saiam bem na resolução de situações desse tipo. O percentual elevado de problemas desse tipo, elaborados pelas professoras, pode servir como alerta, pois sinaliza que elas estão reforçando um conhecimento que os alunos já dominam.

O número de problemas com maior grau de complexidade foi muito pequeno. A $3^{\mathrm{a}}$ extensão teve $9,1 \%$, a $2^{\mathrm{a}}$ extensão $2,3 \%$, a $4^{\mathrm{a}}$ extensão $4,5 \%$ do total. Da $1^{\mathrm{a}}$ extensão, as professoras não elaboraram nenhum problema.

O Gráfico 4 mostra que, no livro de Matemática adotado pela escola, o maior número de problemas de adição e de subtração, cuja resolução envolve somente um raciocínio, está na categoria transformação $(48,9 \%)$, seguido pela categoria composição $(32,6 \%)$ e, por último, a categoria comparação $(18,5 \%)$. É possível perceber uma semelhança desses dados com os do Gráfico 3, que informa sobre os problemas de adição e de subtração elaborados pelas professoras. Tanto na elaboração das professoras, como no livro de Matemática adotado pela escola, a maior quantidade de problemas foi classificada na categoria transformação.

Também, da mesma forma que os problemas elaborados pelas professoras, no livro de Matemática adotado pela escola, a maior concentração está no tipo protótipo, 65,2\% do total. Como já foi dito antes, esse tipo de situação é de pouca complexidade e, por isso, são considerados fáceis. Nos livros, o número de problemas elaborados nas extensões foi muito variado. Houve um maior número nas situações de comparação - $3^{\mathrm{a}}$ extensão, 17,4\% do total, 
seguido por situações da $1^{\mathrm{a}}$ extensão, $10,8 \%$ do total. Da $4^{\mathrm{a}}$ extensão, foram encontrados $5,4 \%$ do total e $1,1 \%$ da comparação - $2^{\mathrm{a}}$ extensão.

\section{Algumas discussões realizadas no estudo com as professoras}

A discussão sobre o ensino do Campo Aditivo, com as professoras, foi o foco central deste estudo e revela aprendizados e dificuldades vivenciados por essas docentes na prática da sala de aula. O movimento de voltar-se para olhar mais detalhadamente o que acontece na sala de aula possibilita que as professoras se interessem mais pelo conteúdo que ensinam. Esse interesse pode proporcionar que haja um maior aprofundamento do conteúdo a ensinar.

Também, comentar com as colegas a experiência de ensino vivenciada e as dificuldades e os sucessos obtidos ao ensinar, além de possibilitar um repensar da prática realizada, oportunizam a superação de incertezas e a construção de aprendizados.

O percurso de aprendizagem das professoras, durante o estudo sobre a resolução de problemas de adição e de subtração, levou em conta que a ação do professor determina, em grande medida, os resultados dos processos de ensino e de aprendizagem (PONTE, 2009) e que o conhecimento aprofundado do conteúdo a ensinar permite ao professor compreender melhor as dificuldades apresentadas por seus alunos (VERGNAUD, 2009). Assim, consideramos pertinente optar por uma experiência de ensino que tem subjacente uma perspectiva baseada na ação-reflexão-ação defendida por Serrazina $(1998,1999)$, e que valoriza a experiência advinda da ação docente praticada na sala de aula. Levando em conta esses aspectos, destacamos algumas discussões coletivas realizadas no estudo do Campo Conceitual Aditivo.

No primeiro encontro, que teve como tema de discussão as situações de composição protótipo, o interesse das professoras foi maior quando se discutiu os dados referentes ao desempenho dos alunos na categoria composição - protótipo e a classificação dos problemas elaborados por elas antes do estudo.

Dos problemas elaborados pelas professoras, classificados como protótipos da categoria de composição, colocamos no slide os cinco abaixo, para serem comentados por elas.

- Na sala de aula, há 19 meninos e 9 meninas. Quantos alunos têm na sala?

- Mamãe comprou 32 laranjas, 17 abacates e 22 maçãs. Quantas frutas mamãe comprou ao todo?

- O pai de José tem 53 anos, a mãe, tem 45. Qual é a soma da idade dos dois juntos? 
- Em um colégio, estudam 1230 alunos no período da manhã e 980, à tarde. Quantos alunos estudam no colégio?

- José tem 8 anos; Maria, sua irmã, 11 e seu primo Antônio tem 9. Quantos anos têm os três juntos?

A maior discussão ficou em torno do quarto problema. As professoras consideraram que desses cinco problemas ele é o mais difícil, pois apresenta números mais altos e, também, porque na opinião delas, é mais difícil armar a conta. A professora, que lecionou uma turma de $2^{\circ}$ ano em 2012, chegou a afirmar que os alunos dela, que passaram para o $3^{\circ}$ ano, resolveriam o cálculo, se a conta estivesse armada.

P. Azul disse: Nesse momento, agora, eu acho que eles teriam dificuldade nessa conta (a conta é $1230+980$ ).

Pesquisadora: A dificuldade seria armar a conta ou realizar a adição?

P. Rosa: A dificuldade seria armar a conta.

P. Azul: Isso, para armar a conta.

Como elas estavam enfatizando somente a questão de armar a conta, foi questionado:

Eles não teriam dificuldade em somar o 8 com o 3 ou o 9 com o 2?

P. Rosa: Na soma, eles sabem, sim. Alguns alunos dela foram meus no ano passado, e eu não sei se eles conseguiriam armar a conta, mas somar, sim.

Pesquisadora: Estou percebendo que a P. Rosa está colocando que as crianças dominam o processo de adição.

P. Rosa: É, dominam.

P. Azul: Sim, se der armado eles resolvem.

P. Rosa: No ano passado eu dava as contas armadas.

A fala das professoras evidencia que para seus alunos a troca de unidades por dezenas não é tão difícil quanto adicionar números com mais de um algarismo. Vergnaud (2009) considera que o problema está na relação entre a regra da adição e as operações que ela representa sobre os objetos e os conjuntos. O autor sugere o trabalho com bases diversas, sobretudo com as pequenas (base três, base quatro), para fazer compreender o paralelismo entre os objetos e o algarismo das unidades e, assim, sucessivamente.

O envolvimento das professoras na discussão sobre o desempenho de seus alunos e sobre a prática realizada em sala de aula evidencia uma postura reflexiva que oportuniza a compreensão do ensino que realizam (ZEICHNER, 2008). Essa capacidade de refletir sobre a prática que desenvolvem na sala de aula pode aprofundar-se na medida em que essas docentes tiverem mais conhecimento (SERRAZINA, 1999), no caso deste estudo, da teoria que aborda o ensino da resolução de problemas de adição e de subtração.

No segundo encontro, que teve como tema de discussão as situações de composição $1^{\mathrm{a}}$ extensão, houve uma discussão sobre a resolução com cálculo mental, e foi questionado:

Por que eu sei que $9+6$ dá 15? Como vocês organizam o pensamento para chegar nesse resultado? 


\section{(Silêncio)}

Pesquisadora: Como vocês pensam para adicionar $9+6 ?$

P. Azul: Cálculo mental.

Pesquisadora: Como fazem o cálculo mental?

(Silêncio)

P. Verde: Êta, os meninos iam somar nos dedos.

Pesquisadora: E vocês, como fazem?

P. Branco: Geralmente eu coloco o maior em cima.

P. Amarelo: Eu digo assim: coloquem o 9 na mente e lembrem-se que vocês têm 9, agora juntem o 6 .

Essa conversa foi importante, porque trouxe para discussão diferentes esquemas de resolução que revelaram algumas condutas (contar nos dedos, partir do primeiro valor, no caso, do número 9) que são orientadas por elas no ensino da resolução dos problemas aditivos. Também, revelou que algumas professoras utilizam "condutas em grande medida automatizadas, organizadas através de um esquema único" (VERGNAUD, 1996a, p. 156), evidenciando que aprenderam a partir de regras e, ainda hoje, repetem essas regras, sem refletirem sobre o processo que está envolvido na resolução.

Quando foi solicitado que observassem as estratégias corretas e incorretas utilizadas pelos alunos, $P$. Violeta comentou:

P. Violeta: o problema é que trabalhamos muito pouco com resolução de problemas.

Pesquisadora: Todos concordam com a fala da P. Violeta, de que vocês trabalham pouco a resolução de problemas?

P. Azul: Eu trabalho pouco, quero ver se este ano trabalho mais.

P. Amarelo: Até eu, este ano eu vejo assim, é importante trabalhar mais problemas. Assim quando chega no $2^{\circ}$ ano o aluno já está com o pensamento mais formado.

Essa discussão revela que as professoras já começaram a perceber que alguns erros dos estudantes ocorrem devido à falta de trabalho com situações-problemas e que os conceitos matemáticos, relativos ao Campo Aditivo, só serão compreendidos por meio de uma abordagem variada de situações (MAGINA et al., 2008).

No momento da elaboração de problemas de composição $-1^{\mathrm{a}}$ extensão para aplicarem a seus alunos, as professoras tiveram dificuldade. Acabavam elaborando problemas nos quais a situação envolvia uma transformação negativa, ou seja, problemas nos quais eram conhecidos o estado inicial e a transformação e era solicitado o estado final. Isso ocorreu, porque, para elas, o que importava é que a resposta envolvesse uma conta de subtração. Alguns problemas elaborados foram os seguintes:

P. Verde: Um livro tem 58 páginas, foram lidas 13 páginas. Quantas páginas faltam para serem lidas?

P. Branco: João tinha, na sua mercearia, 680 laranjas. Vendeu 350 laranjas. Quantas ainda têm para serem vendidas? 
Pesquisadora: $O$ nosso propósito hoje é o de elaborar situações que envolvam duas partes e o todo. Nessas situações, onde estão as duas partes que irão formar o todo?

A pergunta possibilitou que a professora do $4^{\circ}$ ano percebesse o que deveria ser diferente na situação e, ela disse: Se eu mudar de laranjas para frutas e depois, cito dois tipos de frutas, acho que vai dar...

Com o intuito de ajudar as colegas, a professora do $1^{\circ}$ ano pediu para ler o problema que elaborou.

P. Amarelo: No estojo de Luan, tem 10 materiais que são lápis e borracha. Seis são lápis, quantas são borrachas?

Essa discussão possibilitou uma reflexão sobre a importância de observar o tipo de situação presente no problema, e não somente o cálculo necessário para sua resolução, pois a definição de um conceito tem relação com a situação que o constitui (VERGNAUD, 1996a).

No terceiro encontro foi possível conversar sobre as estratégias corretas utilizadas pelos estudantes nos problemas que elas elaboraram no encontro anterior, pois as professoras fizeram registros das mesmas. As crianças dos $1^{\circ}$ e $2^{\circ}$ anos revelaram conhecer esquemas semelhantes, utilizando desenhos, contagem nos dedos, cálculo mental e conta armada. As crianças do $5^{\circ}$ ano resolveram com a conta armada. Quanto às estratégias incorretas utilizadas por eles, o erro mais frequente cometido pelos estudantes do $1^{\circ}$ e $2^{\circ}$ anos foi armar a conta e, pelos estudantes do $5^{\circ}$ ano, foi resolver a adição ou a subtração presente no algoritmo.

Essa postura de refletir sobre a sua ação em sala de aula e sobre o desempenho de seus estudantes, destacada por Serrazina (1999), possibilita que as professoras descubram soluções, sejam delas próprias ou oriundas da discussão coletiva, para superar problemáticas surgidas na prática de ensinar a resolução de problemas.

Para provocar uma discussão sobre o uso de diferentes esquemas de resolução, solicitamos que se reunissem e distribuímos uma folha de papel A4 com quatro problemas, elaborados por elas no instrumento aplicado antes do estudo no grupo, para serem resolvidos com mais de um procedimento de representação da solução. Algumas maneiras deveriam ser com a conta armada e outras sem armar a conta.

O primeiro problema proposto na atividade foi o seguinte: $O$ pai de José tem 53 anos; a mãe tem 45. Qual é a soma da idade dos dois juntos?

As professoras do $1^{\circ}$ e $2^{\circ}$ anos quiseram começar, comentando como haviam pensado. 
P. Amarelo: No primeiro problema, encontramos duas possibilidades de solução sem armar a conta: uma foi o material dourado, representamos com desenhos o material e, a outra, foi a conta deitada (expressão matemática). Com a conta armada só pensamos na possibilidade 53

$+45$

98

A dupla do terceiro ano, em todos os problemas, quando solicitava uma resolução sem a conta armada, representou por meio da expressão matemática e, quando solicitava a conta armada, o cálculo apresentado acima. As professoras do $4^{\circ}$ e $5^{\circ}$ anos, no espaço que solicitava a conta, além das possibilidades das professoras do $3^{\circ}$ ano, fizeram o seguinte procedimento:

\begin{tabular}{rrr}
50 & 3 & 90 \\
+40 & +5 & +8 \\
\hline 90 & 8 & 98
\end{tabular}

A partir do procedimento apresentado por elas, questionamos: O que vemos nessa possibilidade apresentada pelas colegas?

P. Amarelo respondeu: Está trabalhando com a decomposição.

Aproveitamos a fala da $P$. Amarelo e exemplificamos três possibilidades de solução sem armar a conta, usando a decomposição.

$$
\begin{array}{lll}
53+40=93 & 50+40=90 & 53+2=55 \\
93+5=98 & 3+5=8 & 55+40=95 \\
& 90+8=98 & 95+3=98
\end{array}
$$

As possibilidades de representação da resolução oportunizaram que as professoras percebessem que é possível resolver o cálculo sem armar a conta, atividade priorizada por elas e, também, porque esse procedimento favoreceu a reflexão para o fato de que é possível que essa maneira de resolução ajudasse os alunos a compreenderem a ação operatória ao fazerem uso de diferentes invariantes (I) e representações (R) para uma mesma situação (S) (VERGNAUD, 1996a).

Em outro momento, quando solicitado que identificassem as estratégias corretas mais utilizadas pelas crianças na resolução do Problema 9 (João tem 10 anos e Eduardo tem 3 anos a mais que ele. Quantos anos tem Eduardo?), as professoras disseram: resolução correta com algarismos e afirmaram que isso acontece porque é a maneira mais praticada, ou seja, é o procedimento que elas mais ensinam e, por isso, o que as crianças mais utilizam.

No penúltimo encontro, as professoras se manifestaram falando sobre a importância desse processo de discussão para o seu trabalho na sala de aula. 
P. Verde: Professora, quando eu vou elaborar um problema eu fico pensando: esse problema é de qual extensão? Eu não chego a dizer que eu aprendi a dar todos os nomes das diferentes categorias e extensões, mas eu estou buscando aplicar mais problema para os meninos.

P. Rosa: Como ela falou, eu também estou buscando aplicar mais problemas e também observando o tipo de problema que será aplicado. Têm uns que eles tiram de letra e, têm outros, que eles sentem mais dificuldade.

A fala das professoras revela que o estudo do Campo Conceitual Aditivo possibilitou que percebessem a necessidade de aumentar e variar o tipo de problema que estavam propondo em suas aulas, para que pudessem oportunizar que seus alunos ampliassem o conhecimento relativo à resolução de problemas de adição e de subtração, pois "é através das situações e problemas a resolver que um conceito adquire sentido para a criança" (VERGNAUD, 1996a, p.156).

\section{Análise dos problemas elaborados pelas professoras depois do estudo no grupo}

Com o objetivo de buscar indícios que revelassem alguma contribuição do estudo do Campo Aditivo na forma das professoras conceberem o ensino da resolução de problemas desse tipo, realizamos análises comparativas das situações-problema elaboradas por elas, nas três aplicações do instrumento (Gráficos 5 e 6).

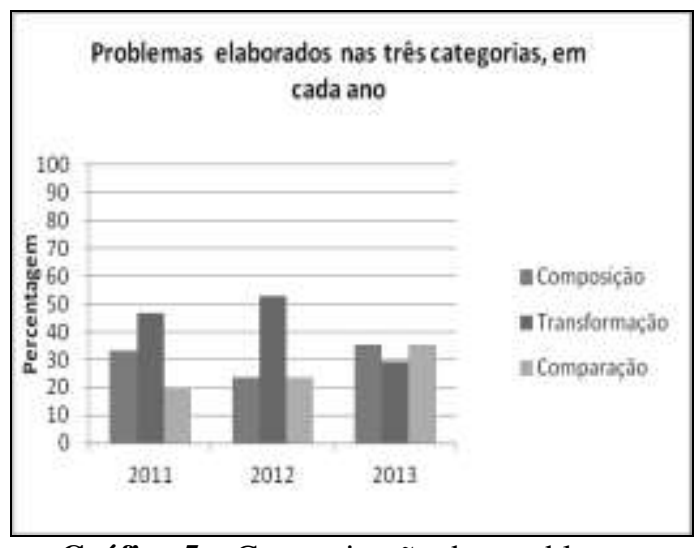

Gráfico 5 - Categorização dos problemas elaborados pelas professoras Fonte: Etcheverria, 2014, p.221

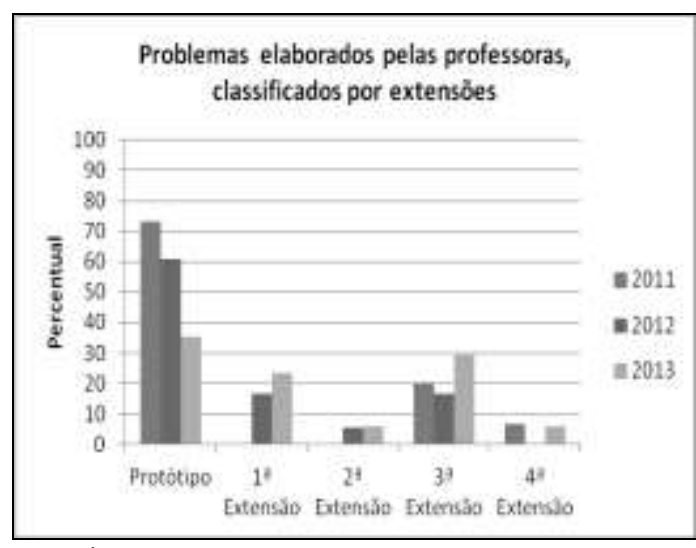

Gráfico 6 - Classificação, por extensões, dos problemas elaborados pelas professoras

Fonte: Etcheverria, 2014, p.222

O Gráfico 5 mostra que, em 2011, antes do estudo com as professoras, e em 2012, após o encerramento dos encontros de estudo com as professoras, o maior número de problemas elaborados por elas foi na categoria transformação. É importante destacar que, em 2012, as professoras não tiveram acesso ao material disponibilizado nos encontros e nem ao livro de Matemática adotado pela escola. Dessa forma, é possível inferir que as situações de transformações são as que as professoras mais dominam e, por isso, são as que primeiro lhes 
vêm à mente e, pode ser, também, que sejam os tipos de situações que elas costumam trabalhar.

Na reaplicação do instrumento, em 2013, as professoras puderam consultar o material dos encontros e o livro de Matemática adotado pela escola. O Gráfico 5 mostra que, nesse ano, houve um equilíbrio entre os índices de problemas elaborados em cada categoria. Isso é muito positivo, pois indica que, com a ajuda do material disponibilizado nos encontros, conseguem revelar a compreensão de que para ajudarem os estudantes a superarem as dificuldades reveladas no diagnóstico e, assim, ampliarem seus conhecimentos sobre o Campo Aditivo, precisam trabalhar situações-problemas de todas as categorias.

A classificação por extensões mostrou o grau de complexidade das situaçõesproblemas elaboradas por essas professoras. O Gráfico 6 deixa claro que, mesmo após o estudo do Campo Conceitual Aditivo, as professoras permaneceram elaborando um maior número de situações prototípicas, de menor complexidade. Contudo, vale destacar que a quantidade de problemas protótipos foi decrescente ano a ano e se aproximou da quantidade dos problemas de maior complexidade, $1^{\mathrm{a}}$ e $3^{\mathrm{a}}$ extensões. É importante observar, também, que em 2013 foram elaborados problemas que envolveram os diferentes graus de complexidade. Esse resultado revela que as discussões realizadas nos encontros criaram condições favoráveis ao entendimento de que precisavam variar o tipo e o grau de complexidade da situaçãoproblema trabalhada.

\section{Desempenho dos estudantes após o estudo com as professoras}

$\mathrm{Na}$ busca de encontrar indícios que revelassem mudanças no desempenho desses estudantes, foi realizada uma análise comparativa dos percentuais de desempenho do grupo de alunos que participou das três aplicações do instrumento (Gráficos 7 e 8).

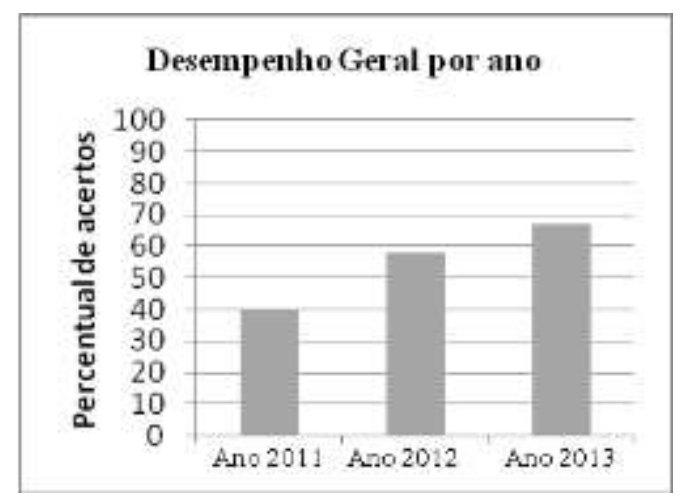

Gráfico 7 - Desempenho geral dos estudantes por ano

Fonte: Etcheverria, 2014, p.211

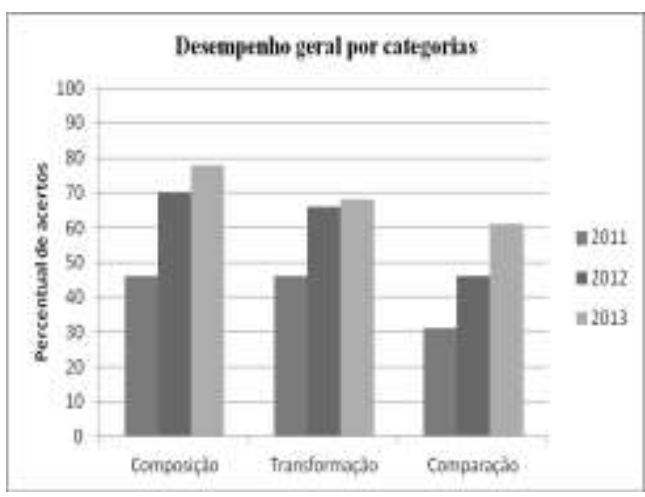

Gráfico 8 - Desempenho geral dos estudantes por categoria

Fonte: Etcheverria, 2014, p.212 
O Gráfico 7 mostra que o desempenho geral dos estudantes foi crescente ano a ano. Esse resultado mostra uma melhora no desempenho, a qual pode estar relacionada ao conhecimento adquirido por meio do trabalho realizado pelas professoras em suas aulas de Matemática, mas, também, deve ser levado em conta o aumento no grau de maturidade das crianças. Considerando-se que o maior índice de crescimento ocorreu do ano de 2011 para o ano de 2012 (18\%), esse indicativo fortalece a ideia de que o trabalho realizado pelas professoras, durante o ano de 2012, ao intensificarem a resolução de problemas em suas aulas de Matemática, produziu alguma mudança no desempenho dos estudantes.

Para observar mais detalhadamente a mudança no índice de desempenho, apresentamos a análise de desempenho geral por categoria. O gráfico 8 mostra que, em todas as categorias, o índice de desempenho foi crescente ano a ano. Na categoria composição, o percentual partiu de 45,9\% em 2011, quando os estudantes estudavam no $2^{\circ}$ ano; aumentou para $70,5 \%$ em 2012 , quando estudavam no $3^{\circ}$ ano; e chegou a 78,8\% em 2013 , no $4^{\circ}$ ano.

O desempenho na categoria transformação esteve um pouco abaixo que o da categoria composição. Partiu do mesmo patamar, 45,8\% em 2011, aumentou para 66,4\% em 2012, e chegou a 67,8\% em 2013. Já no período de 2012 para 2013, o desempenho ficou praticamente estagnado, tendo um aumento de $1,4 \%$.

$\mathrm{Na}$ categoria comparação, o desempenho foi o mais baixo. Partiu do patamar de 30,6\% em 2011, aumentou para $46 \%$ em 2012, e chegou a 61,4\% em 2013, um aumento anual de $15,4 \%$.

\section{Considerações finais}

A análise comparativa do desempenho geral dos estudantes nos problemas do instrumento aplicado revelou um avançou ano a ano e, também, quando analisado por categorias, verificou-se que houve aumento no índice de cada uma delas, contudo o maior avanço foi na categoria composição. Esses avanços podem ser compreendidos como resultado das contribuições do estudo sobre o Campo Conceitual Aditivo realizado com as professoras.

A análise da experiência de ensino mostra que as professoras ampliaram o trabalho com a resolução de problemas aditivos e a classificação dos problemas elaborados por elas indica um equilíbrio entre os índices de problemas de cada categoria. Esses dados sinalizam a compreensão de que para ajudarem seus alunos na superação das dificuldades discutidas nos encontros de estudo precisam intensificar o trabalho com a resolução de problemas e abordar 
situações de diferentes categorias. Contudo, apesar disso, é possível perceber que, mesmo após o estudo, elas continuaram elaborando, em maior número, as situações com baixo grau de complexidade.

Os resultados obtidos sugerem que os problemas presentes no livro de Matemática orientam o trabalho realizado pelas professoras na sala de aula. É possível que as professoras estivessem enfatizando situações-problemas com pequeno grau de complexidade, pois, também no livro, essas situações são enfatizadas, em detrimento das situações que exigem raciocínios mais complexos. E, como consequência, nessas situações-problemas, os estudantes tiveram melhor desempenho.

Ressaltamos que se faz necessário discutir mais sobre a ênfase dada pelas professoras ao procedimento da conta armada, como única forma de representação, resultado já identificado por Reges (2006), e na dificuldade evidenciada pelos estudantes em utilizarem essa forma de representação, por considerarmos que as mesmas podem ser uma condição que restringe o processo de ensino e de aprendizagem do Campo Conceitual Aditivo.

\section{Referências}

ABRANTES, P.; SERRAZINA, L.; OLIVEIRA, I. A Matemática na Educação Básica: reflexão participada sobre os currículos do ensino básico. Lisboa: Ministério da Educação / Departamento da Educação Básica, 1999.

ETCHEVERRIA, T. C. O Ensino das Estruturas Aditivas junto a Professoras dos Anos Iniciais do Ensino Fundamental. 2014. 252 f. Tese (Doutorado em Educação Matemática) - Universidade Anhanguera de São Paulo, São Paulo, 2014.

MAGINA, S. et al.. Repensando adição e subtração: contribuições da teoria dos campos conceituais. 3. ed - São Paulo: PROEM, 2008.

NACARATO, A. M.; MENGALI, B. L. S.; PASSOS, C. L. B. A matemática nos anos iniciais do ensino fundamental: tecendo fios do ensinar e do aprender. Belo Horizonte: Autêntica, 2009.

POLETTINI, A. Mudança e desenvolvimento do professor: o caso de Sara. Revista Brasileira de Educação, Rio de Janeiro, n. 9, p. 88-98, Set/Out/Nov/Dez, 1998. Disponível em: <http://www.anped.org.br/rbe/rbedigital/RBDE09/RBDE09 06 CARLOS MARCELO.pdf > Acesso em: 10 out. 2013.

PONTE, J. P. O novo programa de Matemática como oportunidade de mudança para os professores do Ensino Básico. Revista Interacções, Lisboa,v. 5, n. 12, p. 96-114, 2009. Disponível em: <http://www.eses.pt/interaccoes >. Acesso em: 10 ago. 2011.

REGES, M. A. G. A prática pedagógica de professoras do II ciclo do ensino fundamental no ensino de estruturas aditivas. 2006. 186f. Dissertação (Mestrado Acadêmico em.Educação) Centro de Educação, Universidade Estadual do Ceará, Fortaleza, 2006. 
SERRAZINA, L. Teacher's development in a period of radical change in primary mathematics education in Portugal. 1998. 406 p. Tese (PhD in Matematics Education) - Institute of Education, Universidade de Londres, Londres, 1998.

SERRAZINA, L. Reflexão, conhecimento e práticas lectivas em Matemática num contexto de reforma curricular no $1^{\circ}$ ciclo. Quadrante: Revista Teórica e de Investigação, Lisboa, v. 8, p.139-167, jul., 1999.

VERGNAUD, G. A classification of cognitive tasks and operations of thought involved in addition and subtraction problems. In: CARPENTER, T., MOSER, J.;ROMBERG, T. Addition and

Subtraction: a cognitive perspective. Hillsdale: Lawrence Erlbaum, 1982. p. 39-59.

VERGNAUD, G. A Teoria dos Campos Conceituais. In: BRUN, Jean (Org.). Didáctica das

Matemáticas. Tradução de Maria José Figueiredo. Lisboa: Instituto Piaget, 1996a, p.155 - 191.

VERGNAUD, G. A trama dos Campos Conceituais na construção dos conhecimentos. Revista do GEEMPA, Porto Alegre, n.4, p.9-20, julho, 1996b.

VERGNAUD, G. A formação de competências profissionais. Revista do GEEMPA, Porto Alegre, n.4, p.63-70, jul., 1996c.

VERGNAUD, G. A criança, a matemática e a realidade: problemas do ensino da matemática na escola elementar. Tradução de Maria Lúcia Faria Moro. Curitiba: Ed. da UFPR, 2009.

ZEICHNER, K. M. Uma análise crítica sobre a "reflexão" como conceito estruturante na formação docente. Educação e Sociedade, Campinas, v. 29, n. 103, p.535-554, maio-ago, 2008. Disponível em: <http://www.cedes.unicamp.br>. Acesso em: 10 out. 2013.

Submetido em Abril de 2015. Aprovado em Junho de 2015. 